\title{
Technological Innovation Adoption in Manufacturing Sector: The Moderator Role of Government Support
}

\author{
Noni Ngisau and Nurhani Aba Ibrahim
}

\begin{abstract}
Investment in technological innovation in Malaysia has been actively developed either through government support or through the firm's initiative to adopt technological innovation. This study examines government support as a moderator between the influencing factors and technological innovation performance in the manufacturing sector. The present study is conducted in the context of Malaysian manufacturing sector using a sample of 445 innovative companies. The results indicate that five indicators were an essential factor in boosting technological innovation adoption. Such support includes technical consultancy, innovation activities, technical support services, proper training of personnel, implementing of productivity and registration of patents, and financial support including excluded duty on imported machinery or equipment, tax-exemption incentives and innovation grants to the firm.
\end{abstract}

Index Terms-Government support, manufacturing sector, technological innovation, innovation activities.

\section{INTRODUCTION}

As broadly recognized, innovation is a fundamental component to achieve better performance in the organization. Economic growth relies on a significant extent on technological innovation. It has been reported that investment in technology in Malaysia depended very much on government support compared to their own firm initiatives [1]. The reluctance to invest in technology due to lack of security, lack of conviction on the benefits to the company, individual characteristics of the owners/managers, financial resource, regulative problems, and expertise [1]-[3].

With the advancement of industrial improvement in Malaysia (from import substitution to export advancement strategies and from low tech to high tech businesses) and the industry's slacking execution at the innovation frontier, the government's role in revitalizing innovative progression is crucial. Also, the uncertainty over R\&D returns discourages firms from investing in R\&D. Stimuli in the type of tax and non-tax motivating forces are expected to quicken the pace of innovation by firms. The significance of the role of the government lies not just in giving the right technological advancement policies, but also in giving monetary and other motivating forces to technology advancements. These motivating forces have a significant effect on a firm's investment choices. By making the fundamental monetary motivators (tax and non-tax), the Malaysian government

Manuscript received April 17, 2020; revised June 22, 2020.

Noni Ngisau is with Universiti Teknologi MARA, Sarawak Branch, Malaysia (e-mail: noni.ngisau@gmail.com).

Nurhani Aba Ibrahim is with Faculty of Business Management, Universiti Teknologi MARA, Sarawak Branch, Malaysia (e-mail: nurhani.ai@gmail.com). plays a pivotal role in stimulating innovation by manufacturers. Even though the government has sought after strategies to empower innovation, contemplates empirically study demonstrating the role of government are constrained to support innovation activities [4].

In order to sustain growth, the government role is crucial in stimulating technological innovation advancement. The government will offer the opportunity for technological transformation and sustainable development through the institution of clear standards and policy goals while being flexible in permitting the firms to use numerous suggests that to achieve those goals [5], [6]. Besides, direct support for $\mathrm{R} \& \mathrm{D}$, tax incentives for investment in property technologies, and alternative technical help initiatives underneath an industrial policy will produce favorable business surroundings. Such support will successively facilitate and sustain innovation and industrial development [7], [8]. As a part of our general understanding of the government's role in practical innovation political beliefs, it is helpful to grasp what innovation is, how innovations occur, and what contributes to thriving innovations. Since the willingness to change, the capability to change, and also the opportunity to change are among the vital elements that are necessary for promoting technological changes, the government policies ought to thus be in place to come up with conditions that support these components [9]. Thus, the purpose of this study is to examine the significance of government support for technological innovation.

\section{THEORETICAL FRAMEWORK}

Amongst all the technology innovation adoption theories, the most comprehensive theories used in firm-level are diffusion of innovation (DOI) and technology-organization-environment framework [10]. For more complex new technology adoption, it is essential to combine more than one theoretical model to achieve a better understanding of the technology adoption phenomenon [11].

The selection of the variables in this research model is based on the concept of the determinants of adoption in DOI theory [12] and TOE framework [13]. Innovation characteristics are represented by relative advantage, complexity and compatibility [14]-[16]. Technology competence will be a predictor to technology context as an adoption driver [17]-[19]. Management support and perceived cost and firm characteristics would be a predictor to organization context; meanwhile, environment context will be predicted by external pressure, partnership quality and regulatory pressure. Government support will be a moderator between antecedent variables (innovation characteristics and technology-organization-environment) and technological 
innovation adoption.

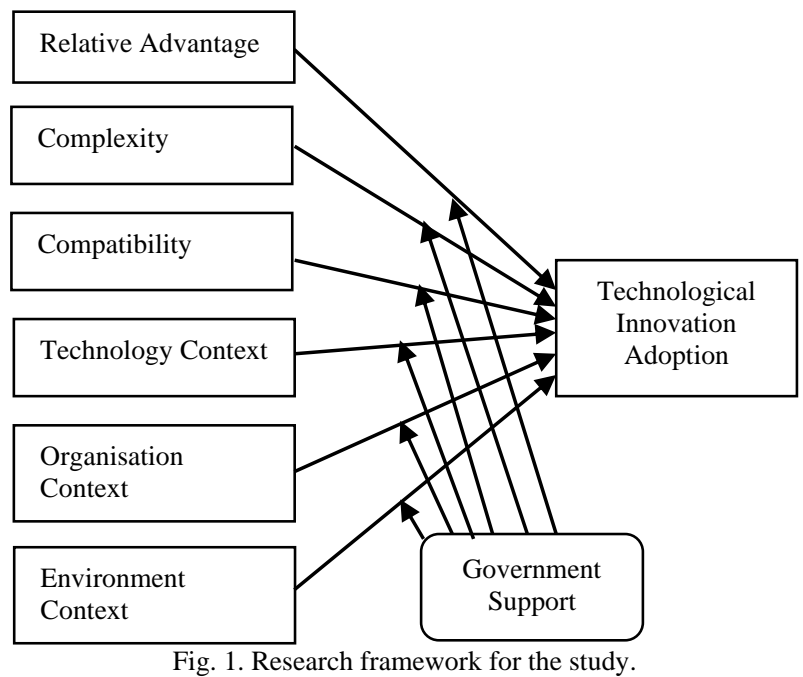

Government support refers to government agencies providing technical support, commercialization, grants and incentives for business industries to adopt new technologies. For example, if the government provides duty-free importation of machinery or equipment for doing the business operation and innovation grant to the firm, this may lead to the innovation adoption. Government support may differ from country to country. A study by [20] found that government support is a critical factor in developing countries. Analysis by [21] on Community Innovation Survey (CIS) for Turkey and Poland find that firms that received government support (in term of buys, modified, or extends its product portfolio or buys new equipment) were considered innovators. In the case of Malaysia, it is essential to determine whether government support is the moderator to the relationship between technological innovation and the innovation characteristic and TOE framework. This study expects government support to moderate the relationship between technological innovation adoption in several ways. Firstly, the government can support in terms of technical consultancy; therefore, the firm will received assistance related to new technology transfer. Secondly, in order to encourage the innovation activities, the government can provide technical support services to enable the firm to evaluate equipment, implementation of productivity improvements and registration of patents. Finally, in terms of financial support, the government can exclude duty on necessary machinery or equipment, give away tax incentive and innovation grant to the firm. Therefore, based on the above arguments, the following hypotheses are proposed:

H1. Government support moderates the relationship between relative advantage and technological innovation adoption.

H2. Government support moderates the relationship between complexity and technological innovation adoption.

H3. Government support moderates the relationship between compatibility and technological innovation adoption.

H4. Government support moderates the relationship between technology context and technological innovation adoption.
H5. Government support moderates the relationship between organizational context and technological innovation adoption.

H6. Government support moderates the relationship between environment context and technological innovation adoption.

The research model will examine whether government support will significantly moderate the effect of all independent variable on the technological innovation adoption as illustrated in Fig. 1.

\section{RESEARCH Methodology}

This study used secondary data; therefore, the adoption of the measurement items for constructs is based comprehensively on the literature review and empirical studies, and the items rely on relevance and availability of the data.

This study used secondary data from National Survey of Innovation (NSI) 2012 commissioned by Malaysian Science and Technology Information Centre (MASTIC) and Ministry of Science, Technology, and Innovation, Malaysia (MOSTI). The NSI 2012 methodology and design of the questionnaire was based on the Oslo Manual (2005) and the Community Innovation Survey (CIS-4) harmonized questionnaire. Total samples of 445 for innovative companies were obtained for data analysis.

Apart from the rich source of information provided by NIS, the selection of the dataset is based on the data characteristics. Based on the quantitative approach applied in this research study, there are some data characteristics issues such as minimum sample size, non-normal data, and scale of measurement. These characteristics issues are among the most stated reasons for adopting the PLS-SEM analysis method (Hair et al., 2012; Henseler et al., 2009).

The measurement variable for government support is show in Table I.

TABLE I: MEASUREMENT FOR GOVERNMENT SUPPORT

\begin{tabular}{ll}
\hline Variable name & \multicolumn{1}{c}{ Statements } \\
\hline GS1 & $\begin{array}{l}\text { Technical consultancy services (e.g. assistance related } \\
\text { to new technologies through technology transfer) } \\
\text { Technical support service (e.g. evaluation of equipment, } \\
\text { implementation of productivity improvements, } \\
\text { registration of patents) }\end{array}$ \\
GS3 & $\begin{array}{l}\text { Duty-free importation of machinery or equipment } \\
\text { The commercialization of R\&D Fund }\end{array}$ \\
GS4 & Tax incentive \\
GS6 & R\&D grant/Innovation grant \\
\hline
\end{tabular}

\section{RESUltS AND DiscuSSION}

The reflective measurement model's evaluation is used to assess their internal consistency reliability and validity. Three specific measures include composite reliability (to evaluate internal consistency), convergent validity (evaluate by individual indicator reliability and average variance extracted (AVE) and discriminant validity (using Fornell-Larcker criterion and cross-loading). This study will assess measurement models, as shown in Fig. 1. The first criterion to evaluate reflective measurement models is typically internal consistency reliability. PLS-SEM priorities the indicators according to their reliability whereby the 
Cronbach's alpha is sensitive to the number of items in the scale and generally tends to underestimate the internal consistency reliability. Therefore, to overcome the limitations, it is appropriate to apply a different measure of internal consistency reliability, which is referred to as composite reliability (CR) [22]. The composite reliability varies between 0 and 1, with higher values indicating higher levels of reliability. In this study, composite reliability values of 0.6 to 0.7 are acceptable since this study considered as exploratory research [23].

The outer loading and average variance extracted (AVE) are considered to establish convergent validity. Indicator reliability must be statistically significant, which at least $50 \%$ explains a substantial part of each indicator's variance. This AVE means that it is an indicator's outer loading should be above 0.708 since that number squared $(0.7082)$ equals to 0.50 . Mostly, indicators with outer loadings between 0.40 and 0.70 ought to be thought-about removal from the dimensions. Only deleting the indicator results in an increase within the composite reliability and the AVE. After performing the assessments, one of the primary constructs relative advantage - is deleted from the model, and all the indicators below 0.58 are dropped from further analysis. Relative advantage is dropped from the measurement model in the event of low indicator outer loading (below 0.5), and if the value of CRs and AVEs do not exceed the threshold value 0.6 to 0.70 and 0.50 , respectively. Table II summaries the results of the reflective measurement model assessment. As can be seen, all model evaluation criteria have been met, providing support for the measures' reliability and validity.

TABLE II: SUMMARY FOR REFLECTIVE MEASUREMENT MODELS

\begin{tabular}{|l|l|l|l|l|l|}
\hline $\begin{array}{l}\text { Latent } \\
\text { Variable }\end{array}$ & $\begin{array}{l}\text { No. of } \\
\text { Item(s) }\end{array}$ & Loading & $\begin{array}{l}\text { Composite } \\
\text { Reliability }\end{array}$ & AVE & $\begin{array}{l}\text { Discriminant } \\
\text { Validity? }\end{array}$ \\
\hline Complexity & 3 & $\begin{array}{l}0.713- \\
0.916\end{array}$ & 0.878 & 0.708 & Yes \\
\hline Compatibility & 4 & $\begin{array}{l}0.631- \\
0.831\end{array}$ & 0.817 & 0.529 & Yes \\
\hline $\begin{array}{l}\text { Technology } \\
\text { Context }\end{array}$ & 4 & $\begin{array}{l}0.699- \\
0.819\end{array}$ & 0.847 & 0.582 & Yes \\
\hline $\begin{array}{l}\text { Organization } \\
\text { Context }\end{array}$ & 7 & $\begin{array}{l}0.709- \\
0.924\end{array}$ & 0.803 & 0.519 & Yes \\
\hline $\begin{array}{l}\text { Environment } \\
\text { Context }\end{array}$ & 5 & $\begin{array}{l}0.603- \\
0.627\end{array}$ & 0.862 & 0.561 & Yes \\
\hline $\begin{array}{l}\text { Technological } \\
\text { Innovation }\end{array}$ & 4 & $\begin{array}{l}0.639- \\
0.809\end{array}$ & 0.874 & 0.638 & Yes \\
\hline $\begin{array}{l}\text { Government } \\
\text { Support }\end{array}$ & 6 & $\begin{array}{l}0.713- \\
0.865\end{array}$ & 0.905 & 0.614 & Yes \\
\hline
\end{tabular}

The PLS-product indicator approach (Henseler \& Chin, 2010) was used to test the moderating effect of government support on the relationship between exogenous latent variable (i.e. complexity, compatibility, technology context, organization context and environment context) and endogenous latent variable (i.e. technological innovation adoption). The product indicator approach involved multiplying each (mean-centered) indicator of the exogenous latent variable with each indicator of the moderator variable. For example, the mean-centered indicator of the predictor (complexity) and the moderator (government support) was multiplied to create an interaction construct to predict overall technological innovation attitude. In this study, complexity comprised three items, and government support consisted of 7 items; thus, the entire interaction constructs comprised a total of 21 items $(3 * 7)$. It was concluded that interaction term complexity and government support had a negative effect on technological innovation adoption (-0.224). Thus, the relationship between complexity and technological innovation adoption revealed a value of 0.134 . If the value on government support were higher (i.e. government support increased by one standard deviation), this would imply that the relationship between complexity and technological innovation adoption would decrease by the size of the interaction term and obtain the value of $0.134-0.224=-0.09$. Hence, when switching costs increased, complexity became less critical for the explanation of technological innovation adoption.

Consequently, a bootstrapping procedure was performed to assess whether the interaction effect was significant. The results of 500 bootstrap samples indicated that the path coefficient of -0.224 for the interaction construct yielded a value of 1.14. Therefore, government support had no significant moderating effect on the complexity and technological innovation adoption. Fig. 2 shows the interaction effect model: Government support as a moderator.

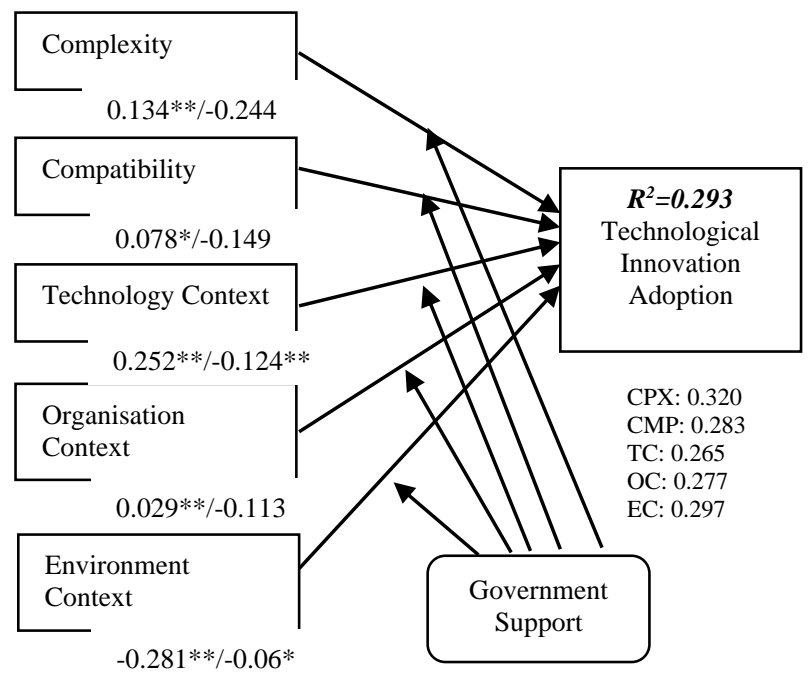

Fig. 2. The interaction effects model: Government Support as a moderator.

Table III shows the moderating effect of government support between antecedent variables (i.e. complexity, compatibility, technology context, organization support and environment support), and exogenous latent variable technological innovation adoption. In the assessment measurement model, there were six forms with seven indicators to predict the moderator government support, i.e. GS1, GS2, GS3, GS4, GS6 and GS7 with factor loading between 0.713-0.865 with AVE and CR above the threshold value of (0.5 and 0.7$), 0.614$ and 0.905 respectively. Indicator 5 was excluded from the construct due to lower factor loading $<0.6$. The moderating effect only supported two exogenous latent variables i.e. technological context $(\beta=-0.124, p<$ $0.01)$ and environment context $(\beta=-0.060, p<0.05)$ on its relationship with technological innovation adoption. Complexity, compatibility, and organizational context, did does not have a significant moderating effect of government support on the relationship with technological innovation adoption. 
TABLE III: THE MODERATING EFFECT OF GOVERNMENT SUPPORT BETWEEN ANTECEDENT VARIABLES

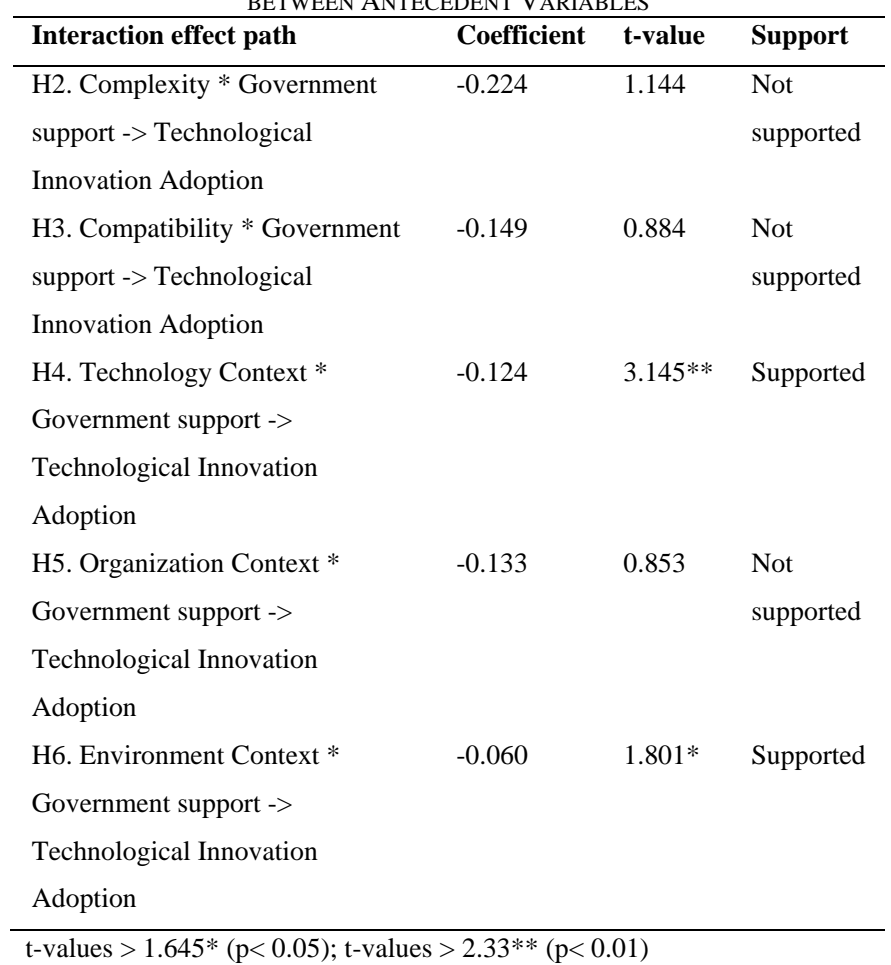

The moderating effect was further assessed by comparing the proportion of variance explained (as expressed by the determination coefficient $R^{2}$ ) of the main effect model as suggested by [24]. The $f^{2}$ effect size was calculated as follows:

$$
f^{2}=\frac{R^{2}{ }_{\text {model with moderator }}-R_{\text {model without moderator }}^{2}}{1-R_{\text {model with moderator }}^{2}}
$$

Therefore, the moderating effects $f^{2}$ effect size on technological context and environment context were 0.0351 (0.317-0.293/1-0.317) and 0.0202 (0.307-0.293/1-0.307) respectively. The results showed that the size of the moderation effect was small $\left(f^{2}=0.02\right.$; Cohen 1988). Consequently, this showed that government support moderated the relationship between technological context, and environment context and technological innovation adoption, thus supporting $\mathrm{H} 4$ and $\mathrm{H} 6$.

Fig. 3 and Fig. 4 shows the plot of this effect created using a template derived from this web site www.jeremydawson.com/slopes.htm. It demonstrates that the relationship between technology context, and environment context and technological innovation adoption. For the technology context, the relationship was positive for high government supports (the High GS) and negative for those with low government support (the Low GS). In other words, less government support provided a less profound effect on the relationship between technology context and technological innovation adoption. Government support was found to constrain or moderate the relationship between technology context and technological innovation adoption. Thus, hypothesis 4 is supported. In the instance of environment context, the plot demonstrates that relationship is positive, the rate of change was more significant for the high government support (the High GS) compared to the low government support (the Low GS). Therefore, this supports hypothesis 6 .

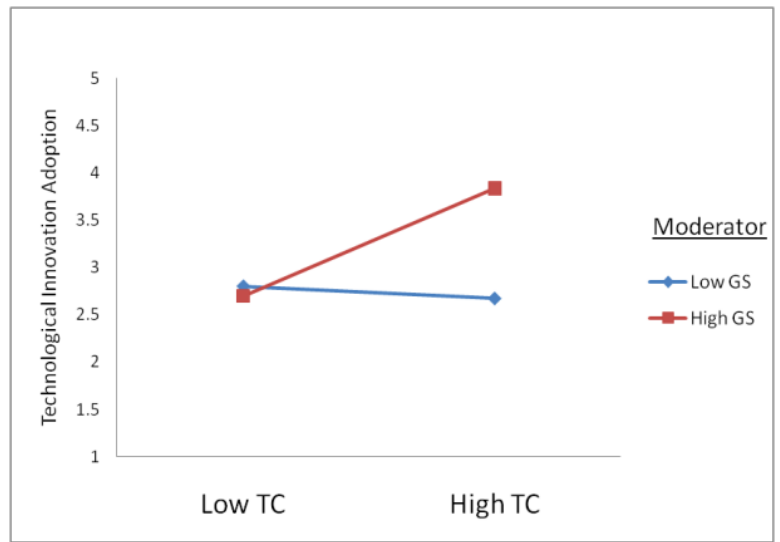

Fig. 3. Moderating effects of government support on the relationship between technology context and technological innovation adoption.

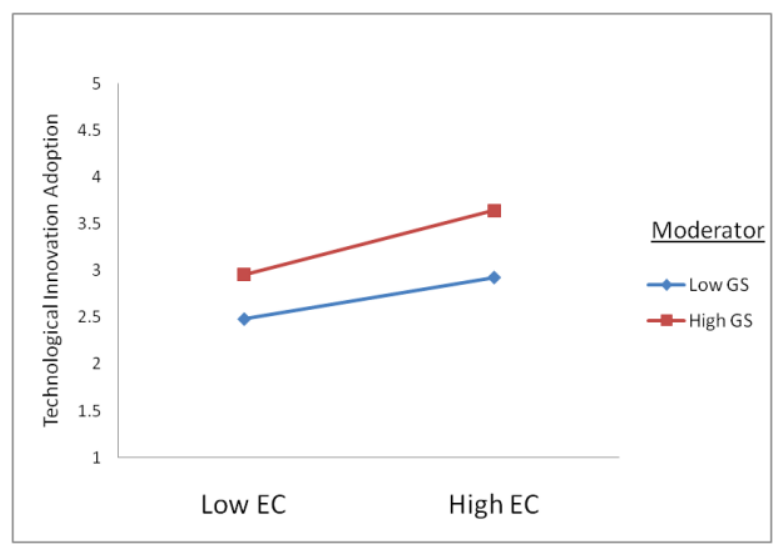

Fig. 4. Moderating effects of government support on the relationship between environment context and technological innovation adoption.

Under H4 and H6 hypotheses, technology context and environment context were moderated by government support in its relationship to technological innovation adoption. The finding could be related to the high cost to purchase the technology and high cost for training, particularly in the context of Malaysian SMEs, which still depend heavily on government funding. Meanwhile, for environment context, it may be due to external pressure, partnership quality and regulatory pressure.

Government support plays an essential role, especially in a developing country [20] in the purchase of advanced machinery or equipment, provision of training, and in the implementation of new marketing method and new organization methods. SMEs, especially in manufacturing sectors, face many setbacks in terms of lack resources such as skill, insufficient capital and others primary resources, and these are among limitations that hinder the fast development of SMEs [25]. By considering the significant roles of SMEs to the nation, government interference and continuously support have become critical to the SMEs through several ways. In the case of government support, five indicators were found to be an essential factor in boosting technological innovation adoption. Such support includes technical consultancy, innovation activities, technical support services, proper training of personnel, implementation of productivity and registration of patents, and financial support including 
excluded duty on imported machinery or equipment, tax-exemption incentives and innovation grants to the firm.

Environment factors have a significant negative effect on the technological innovation adoptions in a direct relationship. Environment factors are the most crucial exogenous variable in the prediction of technological innovation adoption. Government support has a more significant influence as a moderator between the environment context and technological innovation adoption whereby the relationship is positive, and the rate of change was more significant with high government support compared to low government support. Often, development policies are favorable to giant enterprises and transnational companies. Inefficiencies in regulative procedures and body processes are usually the common constraints on the business setting for SMEs. SMEs found the processes and procedures for registration, licensing, and permits onerous, led to a high price of compliance and low productivity. Alternative critical constraints on the regulative and body framework were the high price of tax compliance because of sophisticated tax administration, corruption caused by weak governance, long customs processes, weak social contract control, and high court proceedings.

\section{IMPLICATIONS AND CONCLUSION}

Government support plays a vital role to the firm in implement of innovation. Successful innovation in firms requires having both external and internal environmental determinants. At the country level, the micro and macroeconomic governmental policies and regulations are intended at strengthening the innovative capabilities of firms and the nation for sustaining competitive advantage and creating economic development. The central government support activities are duty-free for import machinery and equipment, tax incentive, R\&D grant, innovation grant, consultancy services and support services.

The findings revealed that government support affected the adoption of technological innovation, which indicates that the firm performed more exceptional innovation performance with high government support in both technology and environment contexts. In other words, less government support provided a less profound effect on technological innovation adoption. The findings encouraged the local government to continue supporting innovation activity, and the manufacturing firm will use the advantages offered by the government to shape future national innovation growth.

\section{CONFLICT OF INTEREST}

The authors declare no conflict of interest.

\section{AUTHOR CONTRIBUTIONS}

All the authors conducted the research. N. Ngisau developed the methodology, worked on literature review, analyzed the statistical data and worked on the results and conclusions. N. A. Ibrahim supervised the research. All authors had approved the final version.

\section{ACKNOWLEDGEMENT}

The authors wish to acknowledge the Ministry of Science,
Technology and Innovation (MOSTI) Malaysia for the research data and support.

\section{REFERENCES}

[1] S. S. Alam and M. K. M. Noor, "ICT adoption in small and medium enterprises: An empirical evidence of service sectors in Malaysia," International Journal of Business Management, vol. 4, pp. 112-125, February 2009.

[2] A. G. Gockel and S. K. Akoena, "Financial intermediation for the poor: Credit demand by micro, small and medium scale enterprises in Ghana A further assignment for financial sector policy?" IFLIP Research Paper, International Labor Organization, March 2002.

[3] J. Hashim, "Information communication technology (ICT) adoption among SME owners in Malaysia," International Journal of Business and Information, vol. 2, no. 2, pp. 221-240, December 2007.

[4] V. C. Govindaraju, G. K. Vijayaraghavan, and V. Pandiyan, "Product and process innovation in Malaysian manufacturing: The role of government, organizational innovation and exports," Innovation, Organization \& Management, vol. 15, pp. 52-68, December 2014.

[5] N. A. Ashford, "An innovation-based strategy for a sustainable environment," Innovation-Oriented Environmental Regulation, vol. 10, pp. 67-107, 2000.

[6] B. A. G. Bossink, "The development of co-innovation strategies: Stages and interaction patterns in interfirm innovation," $R \& D$ Management, vol. 32, no. 4, pp. 311-320, September 2002.

[7] R. R. Nelso and N. Rosenberg, Technical Innovation and National systems, National Innovation System: A Comparative Analysis, Oxford University Press, 1993.

[8] M. Porter, "The contributions of industrial organization to strategic management," Academy of Management Review, vol. 6, no. 4, pp. 609-620, October 1981.

[9] P. Patanakul and J. K. Pinto, "Examining the roles of government policy on innovation," Journal of High Technology Management Research, vol. 25, no. 2, pp. 97-107, 2014.

[10] M. A. Hammed, S. Counsell, and S. Switf, "A conceptual model for the process of IT innovation adoption in organizations," Journal of Engineering and Technology Management, vol. 29, pp. 358-390, July 2012.

[11] T. Oliveira and M. F. Martins, "Understanding e-business adoption across industries in European countries," Industrial Management \& Data System, vol. 110, no. 9, pp. 1337-1354, September 2010.

[12] E. M. Rogers and M. Everett, Diffusion of Innovation, 3rd ed. The Free Press, 1983.

[13] L. G. Tornatzky and K. J. Klein, "Innovation characteristics and innovation adoption-implementation: A meta-analysis of findings," IEEE Transactions on Engineering Management, vol. 29, no. 1, pp. 28-45, February 1982

[14] T. Oliveira, M. Thomas, and M. Espadanal, "Assessing the determinants of cloud computing adoption: An analysis of the manufacturing and services sectors," Information \& Management, 2014.

[15] H. F. Lin, "Understanding the determinants of electronic supply chain management system adoption: Using the technology-organization-environment framework," Technological Forecasting \& Social Change, vol. 86, pp. 80-92, July 2014.

[16] I. Wu and C. Chuang, "Examining the diffusion of electronic supply chain management with external antecedents and firm performance: A multi-stage analysis," Decision Support Systems, vol. 50, no. 1, pp. 103-115, 2010.

[17] Y. M. Wang, Y. S. Wang, and Y. F. Yang, "Understanding the determinants of RFID adoption in the manufacturing industry," Technological Forecasting \& Social Change, vol. 77, pp. 803-815, 2010.

[18] T. Oliveira, M. F. Martins, and U. N. Lisbon, "Literature review of information technology adoption models at firm level," Electronic Journal of Information Systems Evaluation, vol. 14, no. 1, pp. 110-121, 2011.

[19] K. Zhu and K. L. Kraemer, "E-commerce metrics for net-enhanced organizations: Assessing the value of e-commerce to firm performance in the manufacturing sector," Information Systems Research, vol. 13 no. 3, pp. 275-295, 2002.

[20] K. Zhu and K. L. Kraemer, "Post-adoption variations in usage and value of e-business by organizations: Cross-country evidence from the retail industry," Information Systems Research, vol. 16, no. 1, pp. 61-84, 2005

[21] K. Szczygielski, W. Grabowski, M. T. Pamukcu, and V. S. Tandogan, "Does government support for private innovation matter? Firm-level evidence from Turkey and Poland," Research Policy, vol. 46, no. 1, pp. 1-121, 2017. 
[22] J. Hair, F. Joe, G. T. M. Hult, C. H. Ringle, M. Christian, and M. Sarstedt, "A Primer partial least Squares structural equation modelling (PLS-SEM)," Sage Publication, 2014.

[23] J. C. Nunally and I. H. Bernstein, Psychometric Theory, 3rd ed. McGraw-Hill, New York, 1994.

[24] J. Henseler and F. Fassott, "Testing moderating effects in PLS path models: An illustration of available procedures," Handbook of Partial Least Squares, pp. 713-735, 2010.

[25] M. N. H. Yusoff and M. R. Yaacob, "The government business support services in Malaysia: The evolution and challenges in the new economic model," International Journal of Business and Management, vol. 5, no. 9, pp. 60-71, 2010

Copyright $\odot 2020$ by the authors. This is an open access article distributed under the Creative Commons Attribution License which permits unrestricted use, distribution, and reproduction in any medium, provided the original work is properly cited (CC BY 4.0).

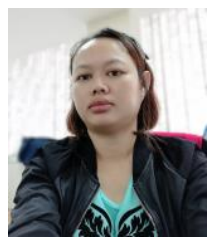

Noni Ngisau graduated with B.Sc in computer science from Universiti Sains Malaysia (USM) in 2001. She took up master of business administrative (MBA) from Universiti Teknologi MARA (UiTM) in 2008 Currently, she is a final-year PhD student in business and management at Universiti Teknologi MARA, Samarahan Campus, Sarawak, Malaysia. She is currently an asset information system executive at Cahya Mata Sarawak Roads Sdn Bhd where her expertise has been utilized in forming asset management and maintenance of State Roads in Sarawak, Malaysia.

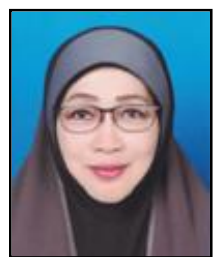

Nurhani Aba Ibrahim is a technical committee member for the National Wage Consultative Council of Malaysian since 2011. The committee is responsible to conduct various studies on labour, wages, and minimum wages and write occasional reports on the implementation of minimum wage in Malaysia. She obtained her $\mathrm{PhD}$ in economics from the University of Leicester, UK (2007), master of business administration from Universiti Teknologi MARA, Malaysia (1999) and bachelor of economics (hons) from the International Islamic University, Malaysia (1992).

She is a senior lecturer at the Department of Economics, Faculty of Business Management, Universiti Teknologi MARA (UiTM), Samarahan Campus, Sarawak, Malaysia. She has more than 25 years of teaching experience at the university. She was also a coordinator for the UiTM-Industry Linkages Centre at the same campus (2009-2011). She had supervised six MSc finance students at the School of Management, University of Leicester (2005-2006) and currently supervises three PhD and two master by research students at the Universiti Teknologi MARA. She was the lead researcher or co-researcher for three Fundamental Research Grant Scheme and a co-researcher of an Exploratory Research Grant Scheme that have been completed. She has co-authored several books, articles in various journals and presented papers in many international conferences.

Dr Nurhani is also a panel evaluator (economics) for the Malaysian Qualifying Agency, member of the Royal Economic Society, Economics Association of Malaysia and Social Science Association of Malaysia. 